\title{
The Use of Sorafenib in Thyroid Cancer
}

\author{
Aneta L Zygulska, ${ }^{1}$ Krzysztof Krzemieniecki² and Anna Sowa-Staszczak ${ }^{3}$
}

1. Senior Lecturer; 2. Associate Professor; 3. Associate Professor, Endocrinological Department, University Hospital, Cracow

\begin{abstract}
There are not effective therapies for metastatic unresectable, non-radioactive iodine (RAl)-avid thyroid carcinomas. Fortunately, thyroid carcinomas represent a promising paradigm for targeted therapy due to the presence of activating mutations of genes coding the kinase tyrosines that are involved in all functions of cancer cells (such as growth or invasion). In this paper, an efficacy and toxicity of sorafenib, one of the multi-kinase inhibitors in thyroid carcinomas treatment, is presented.
\end{abstract}

\section{Keywords}

Thyroid carcinoma, multi-kinase inhibitor, sorafenib

Disclosure: The authors have no conflicts of interest to declare.

Received: 8 January 2013 Accepted: 27 January 2013 Citation: European Endocrinology, 2013;9(1):28-31 DOI: 10.17925/EE.2013.09.01.28

Correspondence: Aneta L Zygulska, Oncological Department, University Hospital, 10 Sniadeckich Street, 31-531 Cracow, Poland. E: zygulska@poczta.onet.pl

Patients with metastatic unresectable thyroid cancer, which does not concentrate radioiodine, have the limited possibilities of treatment because there is no effective treatment options in these group of patients. The role of external beam of radiotherapy and chemotherapy is minimal in these cases.

Protein kinases are involved in transmitting intracellular signals that eventuate in all biological properties for cancer cells including growth, survival, invasion and metastasis. ${ }^{1}$ Preclinical models have shown that inhibition of main kinase steps in the mitogenic and angiogenic signalling pathways can have antitumoural effects.

Thyroid carcinomas represent a particularly promising paradigm for targeted therapy because of the major oncogenic events are activating mutations of genes coding the kinase tyrosines and these occur early in the cancer development. ${ }^{1}$

Sorafenib (BAY 43-9006) is one of the oral multi-kinase inhibitors targeting the serine/threonine kinases RAF1 and inhibiting several tyrosine-kinase receptors including RET and involved in tumour neovascularisation: vascular endothelial growth factor receptors 2 and 3 (VEGFR 2 and VEGFR 3), platelet-derived growth factor receptor beta (PDGFR), C-KIT, Flt-3. ${ }^{2-4}$ In addition, sorafenib inhibits wild-type and mutant BRAF V600E. ${ }^{4}$ Overexpression of VEGFR and other growth factors is commonly found in tumours of thyroid origin particularly those having BRAF mutations. ${ }^{5}$ These findings provided the rationale for using sorafenib in patients with metastatic, non-radioactive iodine (RAl)-avid thyroid cancer. ${ }^{5}$ The drug may potentially inhibit thyroid cancer growth both through anti-proliferative and anti-angiogenic mechanisms. ${ }^{2-4}$

Sorafenib is approved as treatment for metastatic clear cell renal carcinoma and advanced, unresectable hepatocellular carcinoma. ${ }^{6}$ Sorafenib is given orally at a dose of $400 \mathrm{mg}$ twice daily until disease progression or unacceptable toxicity.
Results of current trials with sorafenib in patients with thyroid carcinomas present Table 1

\section{Differentiated Thyroid Carcinoma}

Although the prognosis for differentiated thyroid cancer is good, about $5 \%$ to $20 \%$ of patients develop distant metastases about half of which does not respond to conventional therapy such as radioactive iodine (RAl). $4,7,8$ Conventional chemotherapy response rate is assessed as a maximum $25 \%$ and chemotherapy causes marked toxicity. For those diagnosed under 45 years with distant metastases survival steadily declines. Long-term survival for patients with stage IV is about $43 \%$ and about $86 \%$ for those with stage I of disease. ${ }^{4}$ In case of RAI-resistant disease overall survival drops to $10 \%$.

All histological subtypes have similar responses for sorafenib therapy. ${ }^{4,9,10}$ Radiological response is not influenced by gender, age or the presence of BRAF V600E mutation. ${ }^{10}$ According to other authors the effect of sorafenib seems to be more potent in patients with papillary thyroid carcinoma than follicular or poorly differentiated carcinoma and with BRAF mutation than with wild-type BRAF.9,11 The response occurs in the lung, but not in the non-irradiated bone and pleural metastases. Lymph nodes respond but less robustly.4,10,11

Patients with bone metastases had significantly worse median progression-free survival and median overall survival than patients without metastases to bones. ${ }^{10,12}$ It suggests a tissue-specific response to therapy. These differences in response seem to be either the result of differential expressions and different inhibitions of various VEGF receptors or due to a non-VEGFR-mediated mechanism, such as differences in drug level in tissues. ${ }^{4}$ In a trial by Ahmed et al. partial response after sorafenib treatment in the patients with lung or liver metastases, but not in patients with thyroid and retrosternal masses, was observed. The authors suggested that sorafenib might be more effective against small volume tumours, the tumour vascularity is the major factor in determining response. ${ }^{2}$ 
Table 1: Clinical Trials with Sorafenib in Patients with Thyroid Cancers (according to Antonelli in modification ${ }^{3}$ )

\begin{tabular}{|c|c|c|c|c|}
\hline Author and Year of Study & Pathway Inhibited & Thyroid Cancer & Results (mPFS) & Responses \\
\hline Kober et al., 2007 & RAF, RET, VEGFR & $5 \mathrm{MTC}$ & Not reported & $\begin{array}{l}1(20 \%)-P R \\
1(20 \%)-C R\end{array}$ \\
\hline Gupta-Abramson et al., 2008 & RAF, RET, VEGFR & 30 DTC & 79 weeks & $\begin{array}{l}7 \text { (23 \%) -PR, } \\
16 \text { (53 \%) -SD }\end{array}$ \\
\hline Kloos et al., 2009 & RAF, RET, VEGFR & $\begin{array}{l}\text { 41PTC } \\
11 \text { FTC } \\
4 \text { ATC }\end{array}$ & 15 months & $\begin{array}{l}6(15 \%)-P R, 23(56 \%)-S D \\
\text { (PTC) } \\
\text { No response (FTC and } \\
\text { ATC) }\end{array}$ \\
\hline Hoftijzner et al., 2009 & RAF, RET, VEGFR & 32 DTC & 58 weeks & $\begin{array}{l}8 \text { (25 \%) -PR } \\
11 \text { (34 \%) -SD }\end{array}$ \\
\hline Lam et al., 2010 & RAF, RET, VEGFR & $\begin{array}{l}5 \text { HMTC } \\
16 \text { SMTC }\end{array}$ & 17.9 months & $\begin{array}{l}\text { Prematurely terminated } \\
\text { HMTC } \\
1(6 \%)-P R \\
14(87 \%)-S D\end{array}$ \\
\hline Cabanillas et al., 2010 & $\begin{array}{l}\text { RAF, RET,VEGFR E7080, } \\
\text { VEGFR (sunitinib) }\end{array}$ & $\begin{array}{l}8 \text { PTC } \\
7 \text { FTC (2 out of } 15 \\
\text { received sunitinib) }\end{array}$ & 19 months & $\begin{array}{l}3(20 \%)-P R \\
9(60 \%)-S D\end{array}$ \\
\hline Ahmed et al., 2011 & RAF, RET, VEGFR & $\begin{array}{l}15 \mathrm{MTC} \\
19 \mathrm{DTC}\end{array}$ & Not reached at 19 months & 24 (73 \%) -SD \\
\hline Capdevila et al., 2012 & RAF, RET, VEGFR & $\begin{array}{l}7 \text { PTC } \\
9 \text { FTC } \\
15 \text { MTC } \\
3 \text { ATC }\end{array}$ & $\begin{array}{l}13.5 \text { months DTC, } \\
\text { 10.5 months MTC, } \\
\text { 4.4 months ATC }\end{array}$ & $\begin{array}{l}11 \text { (32 \%) -PR, } \\
14(41 \%)-S D\end{array}$ \\
\hline Savvides et al., 2012 & RAF, RET, VEGFR & 20 ATC & 1.9 months & $\begin{array}{l}2(10 \%)-P R, \\
5(25 \%)-S D\end{array}$ \\
\hline Schneider et al., 2012 & RAF, RET, VEGFR & 26 DTC & 18 months & $\begin{array}{l}8 \text { (31 \%) -PR, } \\
11 \text { (42\%) -SD }\end{array}$ \\
\hline
\end{tabular}

$C R=$ complete response; $D T C=$ differentiated thyroid carcinoma; $F T C=$ follicular thyroid carcinoma; $H M T C=$ hereditary medullary thyroid carcinoma; $M T C=$ medullary thyroid carcinoma; $P R=$ partial response; $P T C=$ papillary thyroid carcinoma; $S D=$ stable disease; $S M T C=$ sporadic medullary thyroid carcinoma; $m P F S=$ median progression-free survival; VEGFR = vascular endothelial growth factor receptor.

Sorafenib appears to be a useful agent in patients with advanced, progressive differentiated thyroid carcinoma and demonstrates welltolerated toxicity profile. ${ }^{13,14}$ Prolonged disease stabilisation is more commonly seen than partial response. $2,6,9,10,15,16$

\section{Papillary Thyroid Carcinoma}

Most of papillary thyroid carcinomas arise as a result of a single activating somatic mutation in one of three genes: translocationproducing RET/PCT oncogenes, BRAF or RAS, with little overlap between them. 1,17,18 RET/PTC oncogenes play an important role in the pathogenesis of papillary thyroid carcinomas arising after radiation exposure and paediatric cancers. ${ }^{1}$ BRAF and RET/PCT mutations are able to activate the MEK/ERK signalling transduction pathway and result in the activation of transcription factors that regulate cellular proliferation, differentiation and apoptosis. ${ }^{17}$

Preclinical findings suggested that sorafenib might offer a potential treatment strategy for papillary thyroid carcinoma sustaining oncogenic activation of RET. ${ }^{19}$

On the basis of papillary thyroid carcinoma cells line carrying the RET/ PCT1 rearrangement and BRAF mutation revealed that papillary thyroid carcinoma cells carrying the RET/PCT1 rearrangement were more sensitive to sorafenib than the cell-carrying BRAF mutation. ${ }^{17}$

However greater efficacy was observed in papillary carcinoma especially with BRAF mutation than in poorly differentiated thyroid carcinoma. Sorafenib had no effect on iodine uptake. ${ }^{20}$ These findings can be helpful to identify patients who most likely respond to sorafenib therapy.

In a Phase II trial, clinical benefit (based on partial remission and stable disease) was six months and more in $56 \%$ of papillary thyroid carcinoma patients. Median duration of partial remission was 7.5 months and median progression-free survival was 15 months. ${ }^{16}$

In a Chinese study, which enrolled nine patients with radioiodinerefractory pulmonary metastases of papillary thyroid carcinoma, a daily dose of sorafenib was smaller (200 mg twice daily) than the standard dose (400 mg twice daily according to drug characteristics) was administered. The results confirmed the efficacy of smaller doses of sorafenib. The objective partial response rate was $33 \%$,the stable disease rate was $44 \%$ and the mean progression free survival was 42 weeks. $^{21}$

Paediatric papillary thyroid carcinoma typically presents with more advanced disease compared with adults, but the prognosis even in the presence of distant metastatic disease is excellent.

One case with progressive RAI-refractory lung metastases from papillary thyroid carcinoma treated with sorafenib has been described in the medical literature so far. After two months of therapy the response was very good. Unfortunately, there are limited data to recommend sorafenib in this kind of tumour. ${ }^{22}$ 


\section{Follicular Thyroid Carcinoma}

Activating mutations of RAS oncogenes occur in approximately $30 \%$ of follicular thyroid carcinomas suggesting that the Ras-Raf-MEK-MAPERK kinase signalling pathway plays a role in the pathogenesis and/or progression of most differentiated thyroid carcinomas. ${ }^{23}$

Results of follicular thyroid carcinoma treatment with sorafenib are contradictive.

In a Phase II trial with 11 follicular thyroid carcinoma or Hurthle cell carcinoma patients with RAl-treatment failure, no objective responses were observed. Progression-free survival was 4.5 months. ${ }^{16}$ In another Phase II trial, Gupta-Abramson et al. achieved $43 \%$ partial remission (in three out of seven patients with follicular thyroid carcinoma). ${ }^{9}$

\section{Medullary Thyroid Carcinoma}

Medullary thyroid carcinoma is a less common, but more aggressive, disease than differentiated thyroid carcinoma. It is treated with total thyroidectomy with or without lymph node excision. Treatment of regional metastatic disease is also based on surgery. It is a RAI-resistant tumour.2,24

About $25-30 \%$ of medullary thyroid carcinomas occur as an inherited disease, the remaining cases represent the sporadic form of this carcinoma. Hereditary medullary thyroid carcinoma can present in three subtypes: as a part of multiple part of neoplasia type 2 (MEN A2 or MEN B2) and as familiar medullary thyroid carcinoma. The most common form of hereditary medullary thyroid carcinoma is MEN A2, in which medullary thyroid carcinoma coexists with phaeochromocytoma and hyperparathyroidism. $18,25,26$

In hereditary medullary thyroid carcinomas, germline RET mutations are the genetic defect causing MEN A2, MEN B2 and familiar medullary thyroid carcinoma in $98 \%$ of cases. ${ }^{25,26}$ According to another source approximately $55 \%$ cases of medullary thyroid carcinomas have mutations of the RET gene, including both inherited and sporadic cases. Tumoural RET mutations, especially M918T, are strong, negative prognostic factors. ${ }^{27}$ RET mutations have not proven so far whether patients will respond to multikinase inhibitors. ${ }^{27}$

For medullary thyroid carcinomas, almost all familiar forms of the disease arise due to inheritable germline-activating mutations in RET, and identical somatic mutations occurring in $\mathrm{C}$ cells commonly causing sporadic disease. 6,19

Preclinical findings suggested that sorafenib might offer a potential treatment strategy for medullary thyroid carcinoma, thus enabling oncogenic activation of RET. ${ }^{19}$

In a small study, five patients with metastatic medullary thyroid carcinoma were treated with sorafenib: one complete remission and one partial remission were described and symptomatic improvement was observed in all patients. ${ }^{28}$

Although only one partial remission was observed in patients with sporadic medullary thyroid carcinoma, $50 \%$ of patients demonstrated stable disease lasting six months or longer, with tumour shrinkage ranging from 8 to $27 \%$ on the basis of Phase $\|$ trial. ${ }^{26}$ The median progression-free survival was 17.9 months and the median overall survival time was not reached at the time of analysis. ${ }^{2}$
According to data from a Phase II UK study in medullary thyroid carcinoma patients the radiological response rate was $25 \%$ and the overall survival - $100 \%$ after 12 months.

The progression-free survival rate of two years in these patients was $84 \%$ and the overall survival rate was $90 \%{ }^{2}$

\section{Anaplastic Thyroid Carcinoma}

Anaplastic thyroid carcinoma represents less than $2 \%$ of all thyroid malignant tumours, but it is responsible for up to $40 \%$ of thyroid cancer mortality. 29,30 Only $10-15 \%$ of patients with this kind of carcinoma lives two years. Anaplastic thyroid carcinoma is usually advanced and unresectable at the time of diagnosis. ${ }^{31,32}$ Age, gender, presence of distant metastasis and local extension are the most important prognostic factors. ${ }^{31}$ Treatment of anaplastic thyroid carcinoma is not standardised and includes surgery, radiotherapy and chemotherapy. ${ }^{31}$

Pathogenesis of anaplastic thyroid carcinoma is closely linked to mutational activation of proteins in the RTK-RAS-MAPK pathway. Ras mutations are more frequent in poorly differentiated and anaplastic thyroid carcinoma (over $50 \%$ ) than in follicular or papillary carcinoma (5-10\%). ${ }^{33}$

BRAF and RAS genes code for kinases that activate signalling through the MAPK pathway, regulating growth and function in both neoplastic and normal cells. According to preclinical models of anaplastic carcinoma cell lines potential efficacy of sorafenib to inhibit MAPK signalling was presented. ${ }^{34}$

In the study by Stenner et al., sorafenib has shown activity against anaplastic thyroid carcinoma in vitro and in vivo, but monotherapy of sorafenib was not enough to alter the course of the disease significantly, most likely due to clonal evolution. An early relapse in form of lymph nodes metastasis reflected sorafenib's limited efficacy in the BRAF exons 11 and 15 unmutated tumour. The concomitant use with radiotherapy was found to be safe. ${ }^{32}$

In a Phase II study, Savvides et al. assessed the efficacy and toxicity of sorafenib in 16 pretreated patients with anaplastic thyroid carcinoma. The disease-control rate (stable disease and partial response) was $40 \%$ and toxicity was manageable. ${ }^{35}$

In a Spanish trial, the response rate was $33 \%$ (one out of three patients with anaplastic thyroid carcinoma who were enrolled). The median progression-free survival was 4.4 months. $^{15}$

Sorafenib demonstrates an acceptable response rate in anaplastic thyroid carcinoma and further clinical trials are warranted, but due to the rarity of this tumour such a trial will be hard to accomplish.

\section{Toxicity}

The side effects of sorafenib differ from the typical anticancer (cytotoxic) drugs. Appetite loss/weight loss, fatigue, hypertension, skin lesions, diarrhoea, hypocalcaemia, hypothyroidism, mucositis and musculoskeletal pain are the most common toxicities. ${ }^{2-4,6,9,10,20,24,26,36}$ Hand-foot reaction and maculo-papular skin rash are the most common dermatological adverse events., ${ }^{2,4}$ In some cases (like other agents inhibit BRAF) sorafenib has been also associated with development of cutaneous squamous cell carcinomas in up to $5 \%$ of treated patients and a similar frequency of keratoacanthomas and other premalignant

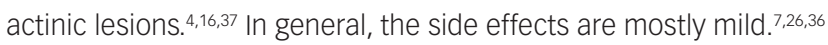


Haematological abnormalities including neutropoenia, Iymphopenia, thrombocytopenia are more common than anaemia during sorafenib therapy. Grade 3 and 4 haematological toxicities seldom occur in thyroid cancer patients receiving sorafenib. ${ }^{36}$

There are described single cases of a myocardial infarction and systolic and diastolic congestive heart failure. ${ }^{10,12,36}$ Rare adverse events such as bleeding and liver toxicity can be fatal. ${ }^{35}$ Doses are reduced in $44-56 \%$ of patients to improve tolerance. 2,9,10,16 Hand-foot syndrome occurs in 76-79\% of patients requiring a dose reduction and is the main dose limiting toxicity. $2,16,26$ Sorafenib holidays are required as a result of adverse events in $63-82 \%$ of patients. 2,9

In the first study reporting long-term effects of sorafenib, the majority of adverse events were seen in the first year of treatment. These side effects were well-tolerated. ${ }^{12}$

Furthermore, treatment of all comorbid conditions (e.g. hypertension) should be optimised and regular thyroid-stimulating hormone (TSH) tests are necessary because of increasing TSH level during sorafenib therapy. Oral thyroid hormonal therapy is administered as needed. ${ }^{20,36}$

\section{Further Investigations}

Studies evaluating efficacy of sorafenib combination with other targeted therapy have either finished or are in progress. ${ }^{38,39}$ One of them is a Phase I trial in which sorafenib was combined with the selective oral farnesyltransferase inhibitor tipifarnib. Farnesylations of Ras is the rate-limiting step in its post-translational modification and is required for its oncogenic activity. ${ }^{39}$
Thirty-five patients with metastatic differentiated and medullary thyroid carcinomas enrolled. The partial response rate was $38 \%$ in medullary thyroid carcinoma and $4.5 \%$ in differentiated thyroid carcinoma. Stable disease of at least six months was $31 \%$ in medullary thyroid carcinoma and $36 \%$ in differentiated thyroid carcinoma. Median progression-free survival was 18 months for all patients. Median overall survival has not been reached so far. Median overall survival was $80 \%$ at two years. Tolerance of treatment was good. ${ }^{40}$

In another study, combination therapy sorafenib and withaferin A (a natural withanolide) showed preclinical anticancer activity against anaplastic and papillary thyroid carcinoma through both anaplastic induction and cell-cycle arrest. ${ }^{41}$

Currently, the Phase III Study of Sorafenib in Locally Advanced or Metastatic Patients with RAI-Refractory Thyroid Cancer (DECISION) has been conducted to test sorafenib in terms of improving progressionfree survival. Patients with follicular, papillary, Hurthle cell and poorly differentiated thyroid carcinoma are being randomised to receive sorafenib or placebo. Results of this trial are eagerly anticipated. ${ }^{42}$

There are more and more published clinical cases confirming high activity of sorafenib in thyroid carcinomas. ${ }^{43,44}$ We treated three patients with metastatic differentiated thyroid carcinoma with very satisfactory results. Among those patients, we observed a case of 58-year-old male with metastatic lesions to the lungs with 26-month partial response to sorafenib. According to our experience, the treatment toxicity of sorafenib in our group of the patients was moderate and easily manageable.
1. Fagin JA, How thyroid tumours start and how it matters: kinase mutants as targets for solid tumours pharmacotherapy, J Endocrinol, 2004; 183(2):249-56 Ahmed M, Barbachano Y, Riddell A, et al., Analysis of the efficacy and toxicity of sorafenib in thyroid cancer: a phase II study in a UK based population, Eur J Endocrino 2011;165(2):315-22.

3. Antonelli A, Fallahi P, Ferrari SM, et al., New targeted therapies for thyroid cancer, Curr Genom, 2011;12(8):626-31. Cabanillas ME, Waguespack SG, Bronstein Y, et al, Trear Treatment with kinase inhibitors for patients with . Anderson experience, I Clin Endocrinol Metab, 2010:95(6):2588-95.

5. Lin JD, Chao TC, Vascular endothelial growth factor in thyroid cancers, Cancer Biother Radiopharm, 2005;20(6):648-61. Sherman SI, Advances in chemotherapy of differentiated epithelial and medullary thyroid cancers, J Clin Endocrinol Metab, 2009;94(5):1493-9.

Johnston LE, Tran Cao HS, Chang DC, Bouvet M, Sociodemographic predictors of survival in differentiated thyroid cancer: results from the SEER database, ISRN Endocrinol, 2012;2012:384707.

8. Shaha AR, Shah JP, Loree TR, Patterns of nodal and distant metastasis based on histologic varieties in differentiated carcinoma of the thyroid, Am J Surg, 1996:172(6):692-4. carcinoma or the thyid, AB 1 , et al., Phase II trial of sorafenib in advanced thyroid cancer JCO, 2008;26(29):4714-19.

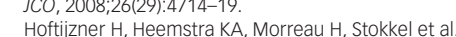
Beneficial effect of sorafenib on tumour progression, but Beneficial effect of sorafenib on tumour progression, but not on radioiodine uptake, in patients with differentiated thyroid carcinoma, Eur J Endocrinol, 2009;161(6):923-31.

11. Schlumberger $M$, Kinase inhibitors for refractory thyroid cancers, Lancet Oncol, 2010;11(10):912-13.

Schneider TC, Abdulrahman RM, Corssmit EP, et al., Long-term analysis of the efficacy and tolerability in advanced radio-iodine refractory differentiated thyroid carcinoma: final results of a phase II trial, Eur J Endocrinol, 2012; 167(5):643-50

13. Sherman SI, Targeted therapies for thyroid cancer, Biochem Pharmacol, 2010;80(5):592-601.

14. Puxeddu E, Romagnoli S, Dottorini ME, Targeted therapies for advanced thyroid cancer, Curr Opin Oncol, 2011;23(1):13-21.

15. Capdevila J, Iglesias L, Halperin I, et al., Sorafenib in metastatic thyroid cancer, Endocr Relat Cancer 2012;19(2):209-16.

16. Kloos RT, Ringel MD, Knopp MV, et al., Phase trial of sorafenib in metastatic thyroid cancer, JCO, 2009;27(10):1675-84.

17. Henderson YC, Ahn SH, Kang Y, et al., Sorafenib potently Inhibits papillary thyroid carcinomas harboring RET/PTC1 rearrangement, Clin Cancer Res, 2008;14(15):4908-14.

18. Lanzi C, Cassinelli G, Nicolini V, Zumino F, Targeting RET for thyroid cancer therapy, Biochem Pharmacol, 2009;77(3):297-309.

19. Carlomagno F, Anaganti S, Guida T, Salvatore G, BAY 439006 inhibition of oncogenic RET mutants, J Natl Cancer Inst, 2006;98(5):326-34.

20. Takami HE, A current status of molecularly targeted drug for the treatment of advanced thyroid cancer, Endocrine $\lrcorner$ for the treatment

21. Chen L, Shen $Y$, Luo Q, et al., Response to sorafenib at a low-dose in patients with radioiodine-refractor pulmonary metastases from papillary thyroid carcinoma, Thyroid, 2011;21(2):119-24.

22. Waguespack SG, Sherman SI, Williams MD, et al., The successful use of sorafenib to treat pediatric papillary thyroid carcinoma, Thyroid, 2009;19(4):407-12.

23. Nikiforova MN, Lynch RA, Biddinger PW, A, et al., Ras point mutations and PAX8-PPAR gamma rearragement in thyroid tumours: Evidence for distinct molecular pathways in thyroid follicular carcinoma, I Clin Endocrinol Metab, 2003;88(5):2318-26.

24. Sherman SI, Targeted therapies for thyroid tumours, Mod Pathol, 2011;24(Suppl. 2):S44-S52.

25. Cakir M, Grossman I. Medullary thyroid cancer: molecular biology and novel molecular therapies, molecular biology and novel molecular th
Neuroendocrinology, 2009;90(4):323-48.

26. Lam ET, Ringel MD, Kloos RT, et al., Phase II clinical trial of sorafenib in metastatic medullary thyroid cancer, $J C O$, 2010;28(14):2323-30

27. Ball DW, Management of medullary thyroid cancer, Minerva Endocrinol, 2011;36(1):87-98.

28. Kober F, Hermann M, Handler A, Krotla G, Effect of sorafenib in symptomatic metastastic medullary thyroid cancer, J Clin Oncol, 2007;25(Suppl. 18):14065.

29. Carcangiu ML, Steeper T, Zampi G, Rosai J, Anaplastic thyroid carcinoma. A study of 70 cases, Am I Clin Pathol, 1985;83(2):135-58.

30. Rosen IB, Asa SL, Brierley JD, Anaplastic Carcinoma of the thyroid gland. In: Textbook of endocrine surgery. Clark $\mathrm{OH}$ Duh QY, Kebebew E (editors), Philadelphia, PA: Elsevier Duh QY, Kebebew E (edit
Saunders, 2005:159-67.

31. Perri F, Di Lorenzo G, Scarpati GDV, Buonerba C, Anaplastic thyroid carcinoma: a comprehensive review of current and future therapeutic options, World I Clin Oncol, 2011;2(3):150-57.

32. Stenner $\mathrm{F}$, Liewen $\mathrm{H}$, Zweifel $\mathrm{M}$, Weber a, et al., Targeted therapeutic approach for an anaplastic thyroid cancer in vitro and in vivo, Cancer Sci, 2008;99(9):1847-52.

33. Garcia-Rostan G, Zhao H, Camp RL, et al., Ras mutations are associated with agressive tumour phenotypes and poor prognosis in thyroid cancer, $J$ Clin oncol, 2003;21(17):3226-35

34. Salvatore $G$, De Falco V, Salerno P, et al., BRAF is a therapeutic target in aggressive thyroid carcinoma, therapeutic target in aggressive thyroid

35. Savvides P, Nagaiah G, Lavertu PN, Fu P, Phase II trial of sorafenib in patients with advanced anaplastic carcinom of the thyroid, Thyroid, 2012; Epub ahead of print.

36. Cabanillas ME, Hu MI, Durand JB, Busaidy NL, Challanges associated with tyrosine kinase inhibitor therapy for metastatic thyorid cancer, I Thyroid Res, 2011;2011:985780. Kong HH, Cowen EW, Azad NS, et al., Keratoacanthomas associated with sorafenib therapy, J Am Acad Dermatol, 2007;56(1):171-2.

38. Gild ML, Bullock M, Robinson GB, Clifton-Bligh R, Multikinase inhibitors: a new option for the treatment of thyroid cancer, Nat Rev Endocrinol, 2011:7(10):617-24.

39. Duntas $L H$, Bernardini $R$, Sorafenib: Rays of hope in thyroid cancer, Thyroid, 2010;20(12):1351-8.

40. Hong DS, Cabanillas ME Wheler t, et al, Inhibition of the Ras/Raf/MEK/ERK and RET kinase pathways with the combination of the multikinase inhibitor sorafenib and combination of the multikinase inhibitor sorafenib and
the farnesyltransferase inhibitor tipifarnib in medullary the farnesyltransferase inhibitor tipifarnib in medullary and differentiated thyroid malignancies, J Clin Endocrino
Metab, 2011;96(4):997-1005.

41. Cohen SM, Mukerji R, Timmermann BN, et al., A nov combination of withaferin A and sorafenib shows synergistic efficacy against both papillary and anaplastic thyroid cancer, Am J Surg, 2012;204(6):895-901.

42. Brose MS, Nutting $\mathrm{CM}$, Sherman SI, et al., Rationale and design of decision: a double-blind, randomized, placebocontrolled phase III trial evaluating the efficacy and safety of sorafenib in patients with locally advanced or metastatic radioactive iodine (RAI)-refractory, differentiated thyroid cancer, BMC Cancer, 2011;11:349-55.

43. Krajewska J, Olczyk T, Roskosz J, et al., Treatment with sorafenib in thyroid advanced cancer - a case report, Endokrynol Pol, 2010;61(5):492-6.

44. Spector E, Franklin MJ, Truskinovky AM, Dudek AZ, Sorafenib induces partial response in metastatic medullary thyroid carcinoma, Acta Oncol, 2010;49(1):104-6. 